\title{
Feeding Artemia and shellfish to phyllosoma larvae of southern rock lobster (Jasus edwardsii)
}

Arthur J. Ritar *, Craig W. Thomas and Adrian R. Beech

University of Tasmania, Tasmanian Aquaculture and Fisheries Institute, Marine Research

Laboratories, Taroona, Tasmania, 7053, Australia

*E-mail address: Arthur.Ritar@utas.edu.au

\begin{abstract}
Newly-hatched phyllosoma larvae from southern rock lobster (Jasus edwardsii) were grown in culture vessels containing 101 sea water in a flow-through system at $18^{\circ} \mathrm{C}$ and fed diets of Artemia sp. and shellfish. The survival and growth of larvae to Stage II was higher when fed ongrown (1.5 mm long) Artemia enriched with Isochrysis galbana (Tahitian strain) at $3 \mathrm{ml}^{-1}$ compared to those fed pieces $(0.5-1 \mathrm{~mm}$ ) of blue mussel (Mytilus edulis planulatus), clam (Katelesia scalarina) or Pacific oyster (Crassostrea gigas) at 0.08 pieces $\mathrm{ml}^{-1}$. There were no differences in survival, size or intermoult interval for newly-hatched larvae grown to Stage III when fed ongrown Artemia only at densities of 1.5, 3 or $6 \mathrm{ml}^{-1}$ or for Stage III larvae grown to Stage VI when fed ongrown Artemia at densities of 1.5, 3 or 6 $\mathrm{ml}^{-1}$ plus mussel $\left(0.04\right.$ pieces $\left.\mathrm{ml}^{-1}\right)$. Stage VI larvae fed ongrown Artemia plus mussel $(0.08$ pieces $\left.\mathrm{ml}^{-1}\right)$ were larger by instar 10 than larvae fed mussel only $\left(0.08\right.$ or 0.16 pieces $\left.\mathrm{ml}^{-1}\right)$. Lower survival became apparent for the mussel-only treatments 205 days after hatch (at Stages IX or X). The pattern of moulting became progressively less synchronised with each successive stage and instar, so that after instar 11 (about Stage IX), it was difficult to discern discrete peaks in the moulting pattern. The first larva reached Stage XI 288 days after hatch. The size of larvae and duration to successive moults, but not survival, were influenced by parent of origin indicating the importance of selection of broodstock in hatchery rearing.
\end{abstract}

Key words: rock lobster, phyllosoma, larval rearing, Artemia, diet

\section{Introduction}

The larval culture of southern rock lobster (Jasus edwardsii) from eggs has proven difficult. A small number of animals has, however, survived through to puerulus settlement in Japan (Kittaka et al., 1988) and New Zealand (Tong et al., 1997) indicating that there is scope for their successful propagation from eggs. This is despite the long, planktonic larval phase, lasting up to two years in the wild (Phillips and Sastry, 1980; Booth and Phillips, 1994) with 11 distinct morphological larval stages (Lesser, 1978) and 17 or more instars (Booth, 1994; Kittaka, 1994a) during development from hatch. The proposed rock lobster aquaculture industry in Tasmania initially intends to access pueruli and young juveniles from the wild but considers that only hatchery production of seedstock will allow sustainability and future industry expansion (Schaap, 1997), so consistent production of pueruli from eggs will be important.

Little is known of the dietary and environmental preferences of the naturally, freeswimming lobster larvae but it is thought that they feed on a variety of zooplankton (Dexter, 1972) and fish larvae (Kittaka, 1999). It is therefore not possible to use a natural diet for large scale culture (Tong et al., 1997). However, larvae in culture will grow and develop through to pueruli when fed diets containing shellfish, Artemia sp. and other live organisms (Kittaka, 1999). Artemia and shellfish are easily produced and dispensed for the 
culture of phyllosoma. Artemia are convenient for feeding because they are readily available, may be ongrown to a larger size and enriched to manipulate their biochemical composition. Larvae are attracted to the swimming behaviour of Artemia and readily capture, eat and extract their nutrients. However, Artemia production is labour intensive and costly.

Artemia nauplii and the meat of blue mussel (Mytilus edulis) are reported to be the most suitable feeds for the early stages of phyllosoma (Kanazawa, 1994). Older phyllosoma appear to prefer Artemia juveniles and other macro-invertebrates (Kittaka, 1994a), as well as fish larvae from several species, either alone or in combination with mussel (Kittaka, 1999). Jasus edwardsii and J. verrauxi have been reared in Japan from egg to puerulus by feeding Artemia nauplii to the first two stages and then mussel gonad to the later stages (Kittaka, 1994a). In New Zealand, Stage I to VIII phyllosoma were fed with 2-3 mm long Artemia enriched with microalgae whilst later stages until settlement were fed with mussel gonad (Booth, 1996). Tong et al. (1997) found that the optimum number and size of Artemia fed to larvae increases at successive stages of development for individually-held larvae. However, it is likely that phyllosoma in mass culture have a different requirement for Artemia density. Also, alternative feeds such as gonad or flesh of several shellfish species may offer a better nutritional profile for development of phyllosoma than is currently possible with Artemia alone. Nevertheless, larvae at $18^{\circ} \mathrm{C}$ fed only $2-3 \mathrm{~mm}$ Artemia reached Stage VII in 75 days (Illingworth et al., 1997) which is considerably less than the 92 and 102 days found for larvae fed Artemia nauplii and mussel flesh (Kittaka et al., 1988).

This study investigated the density of Artemia and shellfish fed to phyllosoma larvae of J. edwardsii from hatch to Stage XI and the effects on larval survival and growth.

\section{Materials and Methods}

Capture and care of broodstock, collection and handling of larvae

Ovigerous rock lobsters weighing 500-700 g were collected from the east coast of Tasmania early in June 1998 and transported to the Marine Research Laboratories, Taroona. They were held at either ambient $\left(9.5-14.5^{\circ} \mathrm{C}\right)$ or constant cool $\left(10.5^{\circ} \mathrm{C}\right)$ water temperatures until egg hatch (late September to late November). Newly-hatched phyllosoma were skimmed from near the water surface of broodstock holding tanks and transferred to 251 buckets where they were disinfected with $25 \mathrm{ppm}$ formaldehyde in sea water for $30 \mathrm{~min}$. The disinfected larvae were rinsed in clean sea water and counted into each culture vessel.

\section{Culture system}

The system for the culture of phyllosoma from hatch to Stage XI of development was described previously (Ritar, 2001). Briefly, sea water was filtered to $1 \mu \mathrm{m}$, heated to $18^{\circ} \mathrm{C}$ and disinfected with ultraviolet radiation before entering circular 351 plastic vessels. Water was jetted through four equally-spaced nozzles positioned near the bottom perimeter of the vessel and another two towards the bottom centre of the vessel. This provided a circular flow to assist phyllosoma movement and mixed the Artemia through the water column. Water volume was maintained at a constant 101 with excess water exiting through a screen (to retain food and phyllosoma) positioned on the wall of the vessel. 


\section{Artemia production}

Artemia cysts (E.G. grade, Artemia Systems, INVE, Belgium) were hatched daily in 501 conical cones at $28^{\circ} \mathrm{C}$ in filtered $(0.2 \mu \mathrm{m})$ sea water and the nauplii grown on blended YM20 (Artemia Systems, INVE, Belgium) and Isochrysis galbana (Tahitian strain) in 3001 conical tanks. The ongrown Artemia at $1.5 \mathrm{~mm}$ (range 1.1 to $1.8 \mathrm{~mm}$ ) length were enriched with I. galbana for $6 \mathrm{~h}$, washed to remove debris and disinfected for $10 \mathrm{~min}$ in $100 \mathrm{ppm}$ formaldehyde before feeding to phyllosoma.

\section{Preparation of shellfish}

The gonads (ovaries and testes) of fresh blue mussel (Mytilus edulis planulatus) or the entire fleshy contents of clam (Katelesia scalarina) or Pacific oyster (Crassostrea gigas) were removed and chopped finely, washed through $1.0 \mathrm{~mm}$ nylon mesh onto $0.5 \mathrm{~mm}$ mesh and the resulting $0.5-1.0 \mathrm{~mm}$ pieces were disinfected with sodium hypochlorite (100 ppm) in sea water for $30 \mathrm{~min}$. The shellfish pieces were resuspended in filtered $(1 \mu \mathrm{m})$, UVtreated sea water and stored on ice until feeding. Larvae at instar 11 and beyond were fed 0.5-1.5 mm mussel pieces (prepared with $0.5 \mathrm{~mm}$ and $1.5 \mathrm{~mm}$ mesh).

\section{Determination of mortalities and moults}

Moults, which disintegrated slowly, were counted daily by removing exuviae floating in the water column or attached to protrusions within the culture vessel. Larval mortalities, which disintegrated quickly, were removed and counted daily and were confirmed by counting all survivors about 5 days after the peak of moulting at each stage. At this time, a sample $(n=15)$ of larvae from each culture vessel was measured for length (from the anterior tip of the cephalic shield between the eyestalks to the posterior tip of the abdomen) and width (left and right extremes of the cephalic shield) on a Nikon 6C Profile Projector (Japan) before returning to the culture vessel. Stages of larval development, determined according to Lesser (1978), were well defined up to and including Stage VIII with one moult (instar) for each stage; thereafter, each successive moult was termed an instar and there were several instars within each stage. Stage IX could be distinguished at instar 11 but it was difficult to assess the number of moults for larvae at Stages X and XI.

\section{Hygiene of culture vessels}

Uneaten food and debris were removed daily in two stages. First, the $250 \mu \mathrm{m}$ screen on the drain outlet was replaced with the $1500 \mu \mathrm{m}$ screen to afford passive escape of the Artemia and much of the suspended debris. Later (3-5 h), the remaining food and debris were siphoned before the $250 \mu \mathrm{m}$ screen was again replaced on the drain outlet. Phyllosoma were transferred weekly (by pouring) into clean vessels after uneaten food and debris were removed from the dirty vessels. Black lids were placed on vessels to maintain darkness except during cleaning and feeding (approximately 2-3 h daily).

\section{Experimental design}

Experiment 1: diet for phyllosoma between hatch and Stage II

This experiment examined the feeding of newly-hatched larvae until Stage II with either:

1. ongrown Artemia $(1.5 \mathrm{~mm})$ at $3 \mathrm{ml}^{-1}\left(30,000 \mathrm{vessel}^{-1}\right)$;

2. mussel (800 pieces vessel ${ }^{-1}$ or 0.08 pieces $\left.^{-1}{ }^{-1}\right)$;

3. oyster $\left(0.08\right.$ pieces $\left.\mathrm{ml}^{-1}\right)$;

4. clam $\left(0.08\right.$ pieces $\left.\mathrm{ml}^{-1}\right)$. 
Larvae from separate female parents were randomly allocated to the culture vessels within each treatment $\left(n=204-224\right.$ larvae vessel $\left.^{-1}\right)$. This was replicated for the larvae from 3 females on separate days of hatch, and their mean \pm SEM $(\mathrm{mm})$ lengths and widths were $2.05 \pm 0.02,2.09 \pm 0.02,2.10 \pm 0.02$, and $1.15 \pm 0.02,1.17 \pm 0.02,1.14 \pm 0.02$, respectively.

Experiment 2: density of Artemia fed to phyllosoma between Stages I and III

In this experiment, newly-hatched larvae were fed $1.5 \mathrm{~mm}$ ongrown Artemia at densities of $1.5,3$ or $6 \mathrm{ml}^{-1}$ until Stage III. Larvae from separate female parents were randomly allocated to the culture vessels within each treatment $\left(n=180-218\right.$ larvae vessel $\left.^{-1}\right)$. This was replicated for the larvae from 3 females on separate days of hatch, and their mean \pm SEM $(\mathrm{mm})$ lengths and widths were $2.06 \pm 0.02,2.05 \pm 0.02,2.11 \pm 0.02$, and $1.06 \pm 0.02,1.15$ $\pm 0.02,1.14 \pm 0.02$, respectively.

\section{Experiment 3: density of Artemia fed to phyllosoma between Stages III and VI}

Larvae ( $n=73-101$ vessel $\left.^{-1}\right)$ at Stage III from Experiment 2 were re-randomised (within 3 female parents of origin) on day 22-24 after hatch and fed $1.5 \mathrm{~mm}$ ongrown Artemia at densities of $1.5,3$ or $6 \mathrm{ml}^{-1}$ until Stage VI. In addition, each treatment was supplemented with mussel $\left(0.04\right.$ pieces $\left.\mathrm{ml}^{-1}\right)$. The mean \pm SEM $(\mathrm{mm})$ lengths and widths of Stage III phyllosoma larvae from the 3 females were $4.09 \pm 0.02,4.05 \pm 0.02,4.35 \pm 0.03$, and 2.40 $\pm 0.02,2.39 \pm 0.02,2.59 \pm 0.02$, respectively.

\section{Experiment 4: diet for phyllosoma between Stages VI and day 205 after hatch}

Larvae ( $\left.\mathrm{n}=55-61 \mathrm{vessel}^{-1}\right)$ at Stage VI from Experiment 3 were re-randomised (within 2 female parents of origin; larvae from one parent discontinued) on day 67-69 after hatch and fed until day 205 after hatch with:

1. ongrown Artemia $(1.5 \mathrm{~mm})$ at $3 \mathrm{ml}^{-1}$ plus mussel $\left(0.08\right.$ pieces $\left.\mathrm{ml}^{-1}\right)$;

2. low mussel - mussel $\left(0.08\right.$ pieces $\left.\mathrm{ml}^{-1}\right)$;

3. high mussel - mussel $\left(0.16\right.$ pieces $\left.\mathrm{ml}^{-1}\right)$.

The experiment was discontinued 205 days after hatch, the remaining larvae were pooled within broodstock parent of origin and fed $1.5 \mathrm{~mm}$ ongrown Artemia at $3 \mathrm{ml}^{-1}$ plus mussel $\left(0.08\right.$ pieces $\left.\mathrm{ml}^{-1}\right)$. The mean \pm SEM $(\mathrm{mm})$ lengths and widths of Stage VI phyllosoma larvae from the 2 females were $7.99 \pm 0.07,8.25 \pm 0.05$, and $4.88 \pm 0.05,5.10 \pm 0.04$, respectively.

\section{Statistical analyses of results}

The influence of treatments on larval dimensions and survival at each stage were analysed by ANOVA. Percentage data were arcsine transformed. Data are presented as mean \pm SEM. When there were significant effects of treatments, comparisons of means were examined using Fisher's protected least significant difference. Analyses were conducted using Statview ${ }^{\mathrm{TM}}$ statistical software.

\section{Results}

Experiment 1: diet for phyllosoma between hatch and Stage II

The total dry weight of diets fed daily to larvae in each culture vessel were similar for chopped mussel, oysters and clams but less than for Artemia (Table 1). Newly-hatched phyllosoma (2.05 $\pm 0.02 \mathrm{~mm}$ long, $1.15 \pm 0.02 \mathrm{~mm}$ wide) fed ongrown Artemia started to 
moult to Stage II at Day 10 after hatch, two days ahead of larvae fed mussel or clam. Artemia feeding also resulted in significantly larger $(P<0.05$ for length and width) Stage II larvae and the survival to Stage II was significantly higher $(P<0.01)$. No larvae moulted when fed oyster.

\section{Experiment 2: density of Artemia fed to phyllosoma between Stages I and III}

The increases in length and width of newly-hatched phyllosoma $(2.08 \pm 0.01 \mathrm{~mm}$ long, $1.11 \pm 0.01 \mathrm{~mm}$ wide) to Stage II and then to Stage III were not significantly different when fed ongrown Artemia at densities of 1.5, 3 and $6 \mathrm{ml}^{-1}$ (Table 2). Survival and the time taken for the first phyllosoma to reach Stage II and then Stage III also did not differ between treatments.

\section{Experiment 3: density of Artemia fed to phyllosoma between Stages III and VI}

The survival and time taken to reach successive stages and the size (length, width) of phyllosoma at Stage III to Stage VI were not significantly different between treatments when fed Artemia at densities of 1.5, 3 and $6 \mathrm{ml}^{-1}$ (Table 3).

\section{Experiment 4: diet for phyllosoma between Stage VI and day 205 after hatch}

Distinct moulting patterns could only be discerned until instar 11 (day 160), which was assessed as Stage IX, and survival between successive stages and instars and overall survival between Stage VI to instar 11 did not differ between treatments (Table 4). However, the survival from Stage VI until day 205 after hatch (Stages IX and X) was significantly higher $(P<0.05)$ for larvae fed Artemia plus chopped mussel than for larvae fed mussel alone. Differences between treatments in larval length and width only became apparent at instar 10 and increased at instar 11 when larvae fed ongrown Artemia plus chopped mussel were larger $(P<0.05)$ than those fed low or high mussel alone.

When the experiment was discontinued 205 days after hatch, only 43 larvae remained (3.6\% survival from hatch). Of these, six larvae survived to Stage XI (first to Stage XI 288 days after hatch) measuring $31.7 \pm 0.2 \mathrm{~mm}$ long and $18.7 \pm 0.3 \mathrm{~mm}$ wide with the largest larva growing to $34.0 \mathrm{~mm}$ long and $20.2 \mathrm{~mm}$ wide on day 363 (at death).

\section{Overall moulting pattern, survival and growth rates}

The overall pattern of larval moulting in experiments 2 to 4 (from Stage I to day 205 after hatch) was similar for the different feeding treatments (data not shown) but was affected by the female broodstock parent from which the larvae originated (Figure 1). There was a high degree of synchrony in moulting of larvae to Stage II from individual broodstock parents of origin but thereafter became less synchronised so that by instar 11 it was difficult to distinguish accurately the peak of moult either within or between broodstock origin. Larvae moulted to the second stage starting 10 days after hatch and the mean $( \pm$ SEM) duration of the interval from hatch was $10.7 \pm 0.3$ days. Thereafter, the intermoult interval to Stages III, IV, V, VI, VII, VIII, and instars 9, 10 and 11 was $10.3 \pm$ $0.3,11.0 \pm 0.0,12.3 \pm 0.7,12.4 \pm 0.7,15.3 \pm 0.9,14.5 \pm 0.4,18.5 \pm 1.2,21.0 \pm 2.5$ and $23.5 \pm 1.2$ days, respectively. The larvae from female \#A took longer to moult through successive stages, so that by Stage VI there was a difference of approximately 7 days between the peaks in moulting of larvae from this female and the other females, and larvae were significantly smaller $(P<0.05$; length and width).

There was no significant effect $(P>0.05)$ of feeding treatment on the mean length of larvae from hatch to instar 10 . However, Figure 2 shows that there was a significant difference $(P<0.05)$ in length and width of newly-hatched larvae from the three 
broodstock parents of origin and the differences increased at subsequent moults to Stage VII. Of the larvae from the remaining two broodstock females, differences were significant $(P<0.05)$ in length and width from instar 10 onwards.

\section{Discussion}

The inclusion of shellfish in the diet of phyllosoma, particularly mussel pieces for older larvae, is advocated because it is assumed that mussel contains a suitable balance of essential amino acids and fatty acids (see review by Kittaka, 1994a). Indeed, Kittaka (1994b) indicated that mussel may be considered a nutritionally complete food. However, it is unclear whether mussel confers any additional nutritional benefit beyond the feeding of Artemia and if so, at what point during larval development the feeding of mussel should begin. Feeding of mussel, oyster or clam alone in this study resulted in poorer growth and survival than for Artemia, and there was an additional problem when feeding clam pieces of adhesion between larvae causing a clumping effect. Few or no larvae survived to Stage II when fed clam or oyster, respectively, whereas many larvae survived to Stage II when fed mussel albeit with a longer intermoult interval and to a smaller size than when fed Artemia. The reason for the better growth and survival when fed Artemia rather than either of the three shellfish species is unlikely due to the higher amount (double) of dry weight fed daily. This is because Experiment 2 and unpublished data showed growth and survival were not significantly different when Artemia were fed at half this rate i.e. at $\leq 1.5 \mathrm{ml}^{-1}$. This suggests that either the nutritional value or the presentation of shellfish in the culture vessel was inappropriate. Further, these newly-hatched larvae swim near the water surface and may remain separated from the inert shellfish pieces on the base of the culture vessel compared with larvae at later stages which tend to be located towards the base. On the other hand, survival and growth of larvae from Stage VI to instar 9 when fed mussel alone was similar to that achieved when fed a combined diet of Artemia and mussel. Beyond instar 10, mussel alone did not maintain as high a growth rate although larval survival was not compromised at instars 10 and 11 . However, after instar 11, survival of larvae fed a mussel-only diet was less than the combined diet.

Phyllosoma may be considered voracious feeders, at least during their early stages. Tong et al. (1997) found that there was an improvement in growth and survival for individual Stage I, II and III phyllosoma when increasing the number of 2-3 mm Artemia fed each day from 1 to 8 and for each subsequent stage to Stage VI when fed up to 16 Artemia day ${ }^{-1}$. Newly-hatched phyllosoma have a dry weight of about $150 \mu \mathrm{g}$ and nearly double their weight at each subsequent stage (unpub. data). Each 2-3 mm Artemia weighs about $20 \mu \mathrm{g}$ $\mathrm{dw}$, so phyllosoma require a high daily consumption of Artemia in proportion to their body weight. However, larvae may not completely consume individual Artemia which then would likely overestimate the food consumption.

The feeding of Artemia to individual larvae (Tong et al., 1997) has not been related systematically to larger-scale culture systems. The dynamics of water movement and the swimming behaviours of Artemia and phyllosoma constitute a complex interaction which needs to be considered and validated for different culture systems. For the medium-scale system used in this study, there was no effect of density of ongrown Artemia fed to newlyhatched phyllosoma up to Stage VI. There is therefore no advantage in feeding at densities outside the range 1.5 to 6 Artemia per ml. Although there was no measurement of the actual rate of consumption of Artemia by individual larvae, it appeared that larvae were fed to excess and that many Artemia were only partly eaten in the $24 \mathrm{~h}$ before removal by cleaning. There were also no apparent problems in accumulation of excessive debris or 
reductions in water quality at the densities examined here. To improve cost efficiencies, further investigation of lower densities of Artemia may be warranted. However, alternatives to Artemia feeding, such as manufactured diets, would greatly reduce costs but more importantly allow complete manipulation of the nutritional profile to suit each stage of larval development.

The difference in intermoult interval and size of larvae from different broodstock suggests that the origin of the broodstock is a significant source of variation. Larvae from one broodstock female moulted progressively later and were smaller than from the remaining two broodstock, and this was most notable by Stage VI. The larval sizes from the remaining two broodstock only differed markedly by instar 10 . This may have not only a genetic component but also an environmental factor stemming from either broodstock nutrition during gamete development or geographical origin (depth, temperature, light influences) of wild-caught animals. MacDiarmid and Kittaka (2000) recently reported that larger larvae at hatch may significantly improve subsequent larval viability and that initial larval size is influenced by a number of factors relating to embryonic development and broodstock source.

\section{Conclusions}

This study showed that phyllosoma larvae of J. edwardsii could be cultured to Stage XI when fed a combination of Artemia and mussel in a flow-through culture system. It is possible that phyllosoma may be fed with Artemia at densities of less than $1.5 \mathrm{ml}^{-1}$ and this warrants further investigation to reduce costs and extraneous biomass from culture. Feeding of mussel alone is not advantageous and may be deleterious for larval culture. It is unclear whether other species of shellfish would also accommodate growth and survival of later stage larvae. Further investigation needs to determine whether the feeding of Artemia alone or in combination with mussel or other shellfish is most suitable. The implications of the differences in growth of larvae from different broodstock are important for the longterm commercial hatchery production of lobsters. It is desirable to have larvae which progress quickly through each stage to reduce the high costs of labour and infrastructure. Therefore, careful selection of broodstock is important to achieve the most rapid rate of larval development.

\section{Acknowledgments}

We would like to thank Bill Wilkinson and the aquaculture technical staff for the invaluable assistance with larval rearing and the production of live feeds. This project was supported by the Fisheries Research and Development Corporation.

\section{References}

Booth, J. D. 1994. Jasus edwardsii larval recruitment off the east coast of New Zealand. Crustaceana 66, 295-317.

Booth, J. D. 1996. Phyllosoma reared to settlement. The Lobster Newsletter 8(2), 1.

Booth, J. D., Phillips, B. F. 1994. Early life history of spiny lobster. Crustaceana 66, 271294.

Dexter, D. M. 1972. Molting and growth in laboratory reared phyllosomes of the Californian spiny lobster, Panulirus interruptus. California Fish and Game 58, 107115 . 
Illingworth, J., Tong, L. J., Moss, G. A., Pickering, T. D. 1997. Upwelling tank for culturing rock lobster (Jasus edwardsii) phyllosomas. Marine and Freshwater Research 48, 911-914.

Kanazawa, A. 1994. Nutrition and Food. In: Phillips, B. F., Cobb, J. S., Kittaka, J. (Eds.), Spiny Lobster Management. Blackwell Scientific Publications Ltd, Oxford. pp. 483494.

Kittaka, J. 1994a. Larval rearing. In: Phillips, B. F., Cobb, J. S., Kittaka, J. (Eds.), Spiny Lobster Management. Blackwell Scientific Publications Ltd, Oxford. pp. 402-423.

Kittaka, J. 1994b. Culture of phyllosomas of spiny lobster and its application to studies in larval recruitment and aquaculture. Crustaceana 66, 258-270.

Kittaka, J. 1999. Importance of three major factors for successful phyllosoma culture. In: Hart, P. R., van Barneveld, R. (Eds.), Proceedings of the 1999 FRDC Rock Lobster Propagation Workshop, 29-31 January 1999, Hobart, Australia. Fisheries Research and Development Corporation, pp. 37-41.

Kittaka, J., Iwai, M., Yoshimura, M. 1988. Culture of a hybrid of spiny lobster genus Jasus from egg to puerulus stage. Nippon Suisan Gakkaishi 54, 413-417.

Lesser, J. H. R. 1978. Phyllosoma larvae of Jasus edwardsii (Hutton) (Crustacea: Decapoda: Palinuridae) and their distribution off the east coast of the North Island, New Zealand. New Zealand journal of marine and freshwater research 12, 357-370.

MacDiarmid, A.B., Kittaka, J. 2000 Breeding. In: MacDiarmid, A. B., Kittaka, J. (Eds.), Spiny lobster: Fisheries and Culture. Blackwell Scientific Publications Ltd, Oxford. pp. 485-507.

Phillips, B. F., Sastry, A. N. 1980. Larval Ecology. In: Cobb, J. S., Phillips, B. F. (Eds.), The Biology and Mangement of Lobsters Vol. 2. Academic Press, New York, pp. 1157.

Ritar, A.J. 2001. The experimental culture of phyllosoma larvae of southern rock lobster (Jasus edwardsii) in a flow-through system. Aquacultural Engineering (in press).

Schaap, A. 1997. Tasmania looks to rock lobster culture. Austasia Aquaculture 11, 40-45.

Tong, L. J., Moss, G. A., Paewai, M. M., Pickering, T. D. 1997. Effect of brine-shrimp numbers on growth and survival of early-stage phyllosoma larvae of rock lobster Jasus edwardsii. Marine and Freshwater Research 48, 935-940. 
Table 1. Effect of diet on survival and growth (mean \pm SEM) and time to moult of Jasus edwardsii phyllosoma larvae from hatch to Stage II (Experiment 1).

\begin{tabular}{|c|c|c|c|c|}
\hline & $\begin{array}{l}\text { Artemia }(1.5 \mathrm{~mm}) \\
\qquad\left(3 \mathrm{ml}^{-1}\right)\end{array}$ & $\begin{array}{c}\text { mussel } \\
\left(0.08 \text { pieces } \mathrm{ml}^{-1}\right)\end{array}$ & $\begin{array}{c}\text { oyster } \\
\left(0.08 \text { pieces } \mathrm{ml}^{-1}\right)\end{array}$ & $\begin{array}{c}\text { clam } \\
\left(0.08 \text { pieces } \mathrm{ml}^{-1}\right)\end{array}$ \\
\hline $\begin{array}{l}\text { Total dry weight }(\mathrm{mg}) \text { fed daily to each } \\
\text { culture vessel }\end{array}$ & $180.0 \pm 45.0$ & $97.0 \pm 2.5$ & $68.7 \pm 11.8$ & $86.7 \pm 6.6$ \\
\hline Survival $(\%)$ to Stage II & $69.8 \pm 15.0^{\mathrm{a}}$ & $35.1 \pm 12.3^{\mathrm{b}}$ & 0 & $8.3 \pm 7.5^{\mathrm{c}}$ \\
\hline First moult to Stage II (days after hatch) & 10 & 12 & - & 12 \\
\hline Larval length $(\mathrm{mm})$ at Stage II & $3.03 \pm 0.03^{\mathrm{a}}$ & $2.65 \pm 0.02^{b}$ & - & $2.56 \pm 0.02^{\mathrm{c}}$ \\
\hline Larval width (mm) at Stage II & $1.88 \pm 0.02^{\mathrm{a}}$ & $1.56 \pm 0.02^{b}$ & - & $1.50 \pm 0.04^{\mathrm{c}}$ \\
\hline
\end{tabular}

Values with different superscripts within each parameter differ significantly $(\mathrm{P}<0.05)$. 
Table 2. Survival and growth (mean \pm SEM) and time to moult of Jasus edwardsii phyllosoma larvae from hatch until Stage III when fed Artemia (ongrown to $1.5 \mathrm{~mm}$ ) at three densities (Experiment 2).

\begin{tabular}{cccc}
\hline & & Artemia density & \\
& $1.5 \mathrm{ml}^{-1}$ & $3 \mathrm{ml}^{-1}$ & $6 \mathrm{ml}^{-1}$ \\
\hline & & & \\
Survival (\%) from: Stage I to II & $36.2 \pm 21.9$ & $76.4 \pm 5.2$ & $62.3 \pm 17.3$ \\
Stage II to III & $64.1 \pm 13.5$ & $62.4 \pm 15.5$ & $69.3 \pm 16.6$ \\
Overall survival (\%) from Stage I to III & $29.0 \pm 21.7$ & $49.3 \pm 14.4$ & $48.9 \pm 19.4$ \\
First moult to: Stage II, Stage III & 10,20 & 10,20 & 10,20 \\
$\quad$ days after hatch) & $3.08 \pm 0.02$ & $3.07 \pm 0.02$ & $3.06 \pm 0.03$ \\
Larval length (mm) at: Stage II & $4.15 \pm 0.03$ & $4.16 \pm 0.03$ & $4.20 \pm 0.04$ \\
$\quad$ Stage III & $1.81 \pm 0.02$ & $1.81 \pm 0.02$ & $1.79 \pm 0.03$ \\
Larval width (mm) at: Stage II & $2.47 \pm 0.02$ & $2.46 \pm 0.02$ & $2.47 \pm 0.03$ \\
& Stage III & & \\
\hline
\end{tabular}


Table 3. Survival and growth (mean \pm SEM) and time to moult of Jasus edwardsii phyllosoma larvae from Stage III until Stage VI when fed Artemia (ongrown to $1.5 \mathrm{~mm}$ ) at three densities with a supplement of 0.04 mussel pieces vessel $^{-1}$ (Experiment 3 ).

\begin{tabular}{cccc}
\hline & & & \\
& & Artemia density & \\
& $1.5 \mathrm{ml}^{-1}$ & $3 \mathrm{ml}^{-1}$ & $6 \mathrm{ml}^{-1}$ \\
\hline & & & \\
Survival (\%) from: Stage III to IV & $86.2 \pm 7.3$ & $82.0 \pm 7.3$ & $80.8 \pm 4.1$ \\
Stage IV to V & $91.2 \pm 2.1$ & $96.2 \pm 4.6$ & $89.3 \pm 7.0$ \\
Stage V to VI & $96.5 \pm 1.2$ & $97.9 \pm 1.5$ & $97.4 \pm 0.8$ \\
Overall survival (\%) from Stage III to VI & $75.1 \pm 7.0$ & $76.6 \pm 3.3$ & $70.8 \pm 8.8$ \\
First moult to: Stage IV, Stage V, Stage VI & $30,40,51$ & $30,40,52$ & $30,40,51$ \\
(days after hatch) & & & \\
Larval length (mm) at: Stage IV & $5.26 \pm 0.05$ & $5.27 \pm 0.05$ & $5.22 \pm 0.04$ \\
$\quad$ Stage V & $6.48 \pm 0.07$ & $6.53 \pm 0.06$ & $6.44 \pm 0.06$ \\
Stage VI & $7.71 \pm 0.11$ & $7.66 \pm 0.11$ & $7.75 \pm 0.11$ \\
Larval width (mm) at: Stage IV & $3.23 \pm 0.04$ & $3.23 \pm 0.04$ & $3.20 \pm 0.04$ \\
Stage V & $3.92 \pm 0.06$ & $3.96 \pm 0.05$ & $3.91 \pm 0.04$ \\
Stage VI & $4.74 \pm 0.07$ & $4.70 \pm 0.08$ & $4.81 \pm 0.07$ \\
\hline
\end{tabular}


Table 4. Survival and growth (mean \pm SEM) and time to moult of Jasus edwardsii phyllosoma larvae from Stage VI to instar 11 (Stage IX) when fed different diets (Experiment 4).

\begin{tabular}{|c|c|c|c|}
\hline & $\begin{array}{l}1.5 \mathrm{~mm} \text { Artemia }\left(3 \mathrm{ml}^{-1}\right) \\
+0.08 \text { mussel pieces } \mathrm{ml}^{-1}\end{array}$ & $\begin{array}{l}\text { Low mussel } \\
\left(0.08 \text { pieces } \mathrm{ml}^{-1}\right)\end{array}$ & $\begin{array}{l}\text { High mussel } \\
\left(0.16 \text { pieces } \mathrm{ml}^{-1}\right)\end{array}$ \\
\hline Survival (\%) from: Stage VI to VII & $93.9 \pm 2.8$ & $94.5 \pm 5.5$ & $95.6 \pm 2.8$ \\
\hline Stage VII to VIII & $87.5 \pm 9.1$ & $95.1 \pm 3.3$ & $92.7 \pm 2.3$ \\
\hline Stage VIII to instar 9 & $97.0 \pm 0.5$ & $88.3 \pm 8.3$ & $92.0 \pm 2.7$ \\
\hline instar 9 to 10 & $84.3 \pm 2.9$ & $84.4 \pm 1.7$ & $90.6 \pm 0.1$ \\
\hline instar 10 to 11 & $67.3 \pm 15.0$ & $62.0 \pm 5.7$ & $45.1 \pm 20.6$ \\
\hline instar 11 to Day 205 & $54.1 \pm 28.0^{\mathrm{a}}$ & $23.0 \pm 0.8^{\mathrm{b}}$ & $18.5 \pm 6.5^{\mathrm{b}}$ \\
\hline Overall survival (\%) from Stage VI to instar 11 & $44.2 \pm 5.8$ & $41.6 \pm 3.4$ & $32.2 \pm 12.5$ \\
\hline Overall survival (\%) from Stage VI to Day 205 & $25.5 \pm 15.5^{\mathrm{a}}$ & $9.6 \pm 0.5^{\mathrm{b}}$ & $5.1 \pm 0.2^{\mathrm{b}}$ \\
\hline $\begin{array}{l}\text { First moult to: Stage VII, VIII, instar } 9 \\
\quad 10,11 \text { (days after hatch) }\end{array}$ & $\begin{array}{r}64,78,96 \\
116,131\end{array}$ & $\begin{array}{r}65,80,97 \\
116,133\end{array}$ & $\begin{array}{r}64,80,96 \\
116,132\end{array}$ \\
\hline Larval length (mm) at: Stage VII & $9.27 \pm 0.09$ & $9.06 \pm 0.08$ & $9.17 \pm 0.11$ \\
\hline Stage VIII & $10.43 \pm 0.15$ & $10.32 \pm 0.12$ & $10.40 \pm 0.11$ \\
\hline instar 9 & $11.83 \pm 0.17$ & $11.41 \pm 0.17$ & $11.28 \pm 0.16$ \\
\hline instar 10 & $13.36 \pm 0.34^{\mathrm{a}}$ & $12.73 \pm .021^{\mathrm{b}}$ & $12.26 \pm 0.23^{\mathrm{b}}$ \\
\hline instar 11 & $15.22 \pm 0.37^{\mathrm{a}}$ & $14.20 \pm 0.21^{\mathrm{b}}$ & $14.23 \pm 0.20^{\mathrm{b}}$ \\
\hline Larval width (mm) at: Stage VII & $5.66 \pm 0.06$ & $5.56 \pm 0.07$ & $5.68 \pm 0.08$ \\
\hline Stage VIII & $6.45 \pm 0.12$ & $6.34 \pm 0.09$ & $6.37 \pm 0.09$ \\
\hline instar 9 & $7.28 \pm 0.12$ & $7.07 \pm 0.11$ & $6.89 \pm 0.11$ \\
\hline instar 10 & $8.24 \pm 0.22^{\mathrm{a}}$ & $7.86 \pm 0.13^{\mathrm{b}}$ & $7.59 \pm 0.14^{\mathrm{b}}$ \\
\hline instar 11 & $9.52 \pm 0.21^{\mathrm{a}}$ & $8.79 \pm 0.14^{\mathrm{b}}$ & $8.85 \pm 0.14^{\mathrm{b}}$ \\
\hline
\end{tabular}

The mean \pm SEM $(\mathrm{mm})$ lengths and widths of Stage VI phyllosoma larvae from two females were $7.99 \pm 0.07,8.25 \pm 0.05$, and $4.88 \pm 0.05$, $5.10 \pm 0.04$, respectively.

Values with different superscripts within each parameter differ significantly $(\mathrm{P}<0.05)$. 

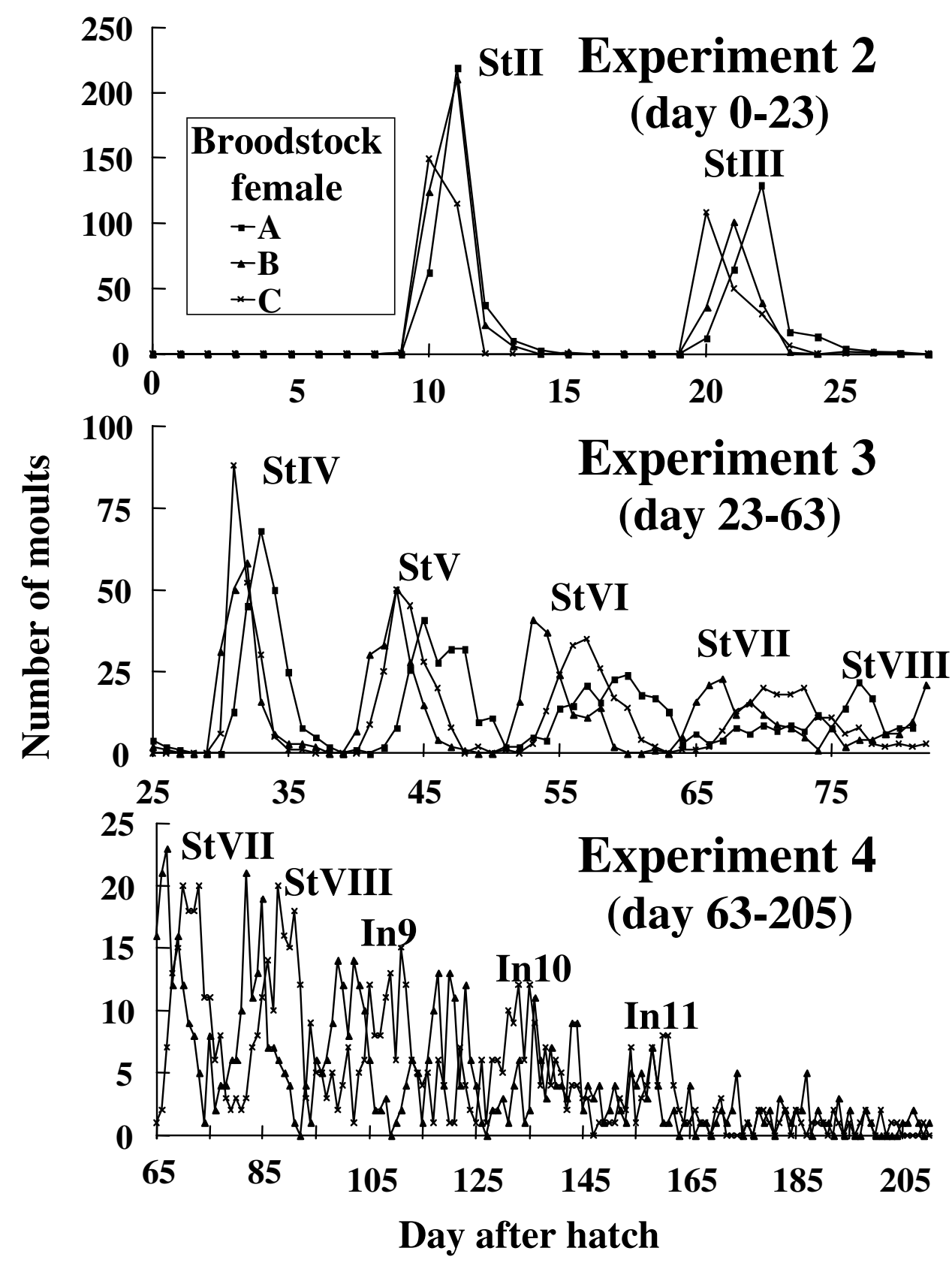

Figure 1. Pattern of moulting of Jasus edwardsii phyllosoma larvae from three females cultured in Experiments 2 to 4 at $18^{\circ} \mathrm{C}$. Experiment 2 commenced with newly-hatched larvae and continued until day 23 after hatch. Experiment 3 commenced with Stage III larvae at day 23 after hatch and continued until day 63 after hatch. Experiment 4 commenced with Stage VI larvae at day 63 after hatch and continued until day 205 after hatch. 


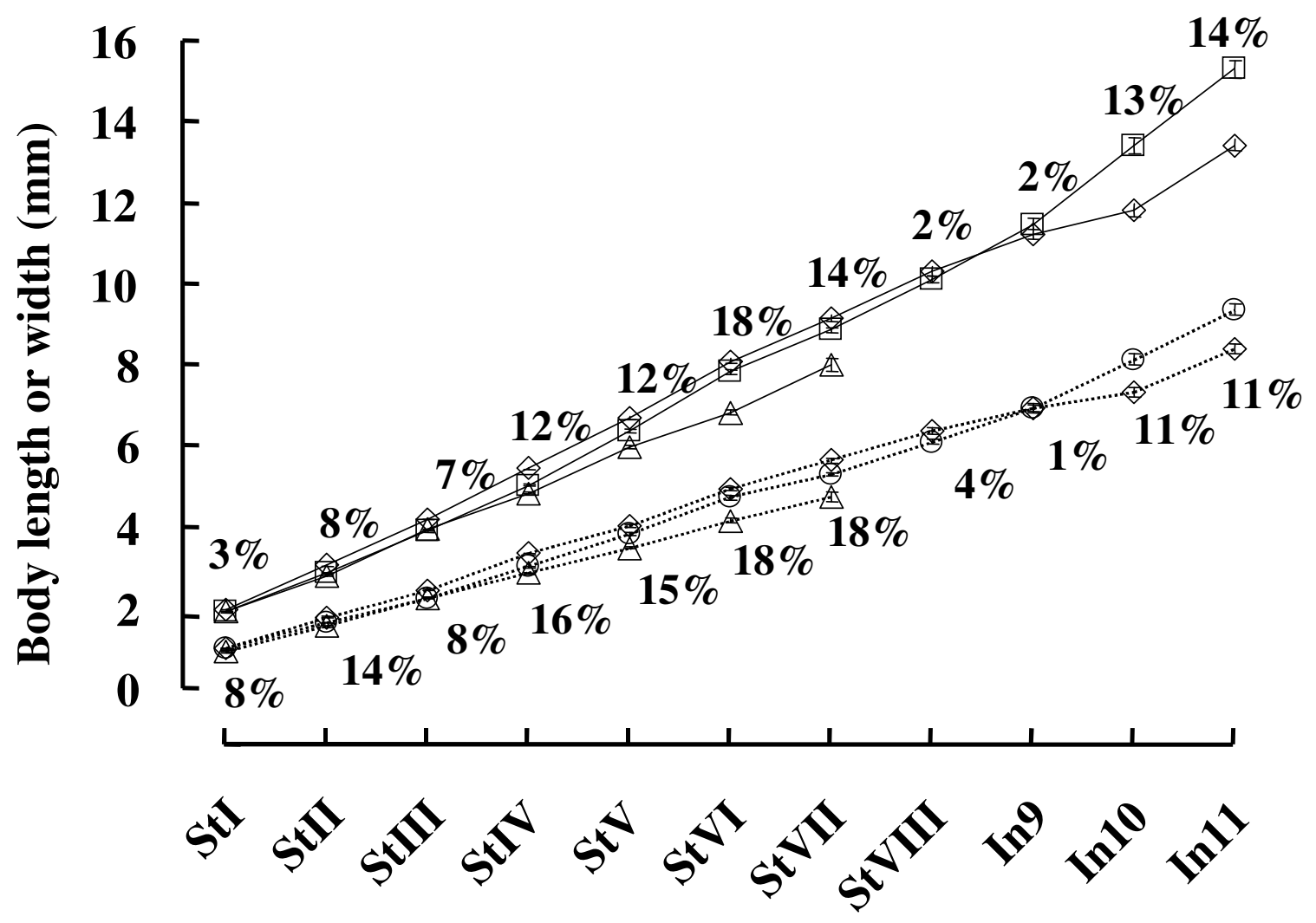

Figure 2. Mean \pm SEM body lengths (solid lines) and widths (dashed lines) of Jasus edwardsii phyllosoma larvae from three females (\#A, triangles; \#B, squares; \#C, diamonds) from hatch to instar 11. Differences between mean largest and smallest larvae at each stage and instar are presented as percentages 